\title{
SOCS1 Regulates the Immunomodulatory Roles of MSCs on B Cells
}

\author{
Lei Zhang ${ }^{1,2,3, *}$, Yan-Nv $\mathrm{Qu}^{2,4, *}$, He-Yang Zhang ${ }^{2}$, Zhen-Yang $\mathrm{Wu}^{1}$, Zhong-Li $\mathrm{Li}^{1}$, \\ Wan-Bei Guo ${ }^{3}$, Qi-Ben Wang ${ }^{3}$, Nan-Zhu Fang ${ }^{5}$, Xiao-Xia Jiang ${ }^{2}$ \\ ${ }^{1}$ Animal Physiology Laboratory, School of Agroforestry Engineering and Planning, Tongren University, Tongren, China \\ ${ }^{2}$ Department of Neural Engineering and Biological Interdisciplinary Studies, Institute of Military Cognition and Brain Sciences, \\ Academy of Military Medical Sciences, Beijing, China \\ ${ }^{3}$ Department of Anatomy, School of Basic Medical Sciences, Xiangnan University, Chenzhou, China \\ ${ }^{4}$ Department of Geriatrics, Peking University Shenzhen Hospital, Shenzhen, China \\ ${ }^{5}$ Laboratory of Animal Genetic Breeding and Reproduction, Yanbian University, Yanji, China
}

Background and Objectives: The effective use of MSCs for the treatment of some B cell-mediated immune diseases is quite limited. The main reason is that the immunomodulatory effects of mesenchymal stem cells (MSCs) on B cells are unclear, and their underlying mechanisms have not been fully explored.

Methods and Results: By co-culturing B cells with MSCs without (MSC/CTLsh) or with suppressor of cytokine signaling 1 (SOCS1) knockdown (MSC/SOCS1sh), we found that MSCs inhibited B cell proliferation, activation and terminal differentiation. Remarkably, the highest inhibition of B cell proliferation was observed in MSC/SOCS1sh co-culture. Besides, MSC/SOCS1sh reversed the inhibitory effect of MSCs in the last stage of B cell differentiation. However, MSC/SOCS1sh had no effect on inhibiting B cell activation by MSCs. We also showed that $\operatorname{IgA}^{+} \mathrm{B}$ cell production was significantly higher in MSC/SOCS1sh than in MSC/CTLsh, although no difference was observed when both MSCs co-cultures were compared to isolated B cells. In addition, MSCs increased PGE2 production after TNF- $\alpha /$ IFN- $\gamma$ stimulation, with the highest increase observed in MSC/SOCS1sh co-culture.

Conclusions: Our results highlighted the role of SOCS1 as an important new mediator in the regulation of B cell function by MSCs. Therefore, these data may help to develop new treatments for B cell-mediated immune diseases.

Keywords: MSCs immunomodulation, SOCS1, B cell

Received: January 1, 2020, Revised: February 26, 2020, Accepted: March 2, 2020, Published online: April 30, 2020

Correspondence to Nan-Zhu Fang

Laboratory of Animal Genetic Breeding and Reproduction, Yanbian University, No.977 Park Road, Yanji, Jilin 133002, China

Tel: +86-13844392153, Fax: +86-433-2732079, E-mail: nzfang@ybu.edu.cn

Co-Correspondence to Xiao-Xia Jiang

Department of Neural Engineering and Biological Interdisciplinary Studies, Institute of Military Cognition and Brain Sciences, Academy of Military Medical Sciences, No.27 Taiping Road, Haidian District, Beijing 100850, China

Tel: +86-18610049161, Fax: +86-10-68166874, E-mail: smilovjiang@163.com

*These authors contributed equally to this work.

(a) This is an open-access article distributed under the terms of the Creative Commons Attribution Non-Commercial License (http://creativecommons.org/licenses/by-nc/4.0/), which permits unrestricted non-commercial use, distribution, and reproduction in any medium, provided the original work is properly cited.

Copyright (c) 2020 by the Korean Society for Stem Cell Research 


\section{Introduction}

Mesenchymal stem cells (MSCs) are pluripotent stem cells that can differentiate into many cell types, such as osteoblasts, chondrocytes, adipocytes, and muscle cells. In addition, it has been found in recent years that MSCs have immunomodulatory capacity and the potential to treat a variety of inflammation-related diseases (1-3). Currently, studies on immune regulation of T cells by MSCs have been extensively provided $(1,4,5)$, but reports on the effects of MSCs on B cell function are rare and present conflicting data (2, 6-11). Some studies have reported that MSCs can promote B cell proliferation, activation, differentiation and antibody secretion $(7-9,12,13)$, while others have shown opposite effects $(10,11,14-18)$. The main reason for this contradiction is that the immune regulation mechanism of MSCs on B cells remains unclear. Consequently, the use of MSCs for the effective treatment of certain immune diseases, such as systemic lupus erythematosus, multiple sclerosis and type 1 diabetes caused by abnormal B cells, is greatly hindered.

Suppressor of cytokine signaling 1 (SOCS1) is an important intracellular negative regulator of cytokine-induced signal transduction. SOCS1 encoding transcripts are usually present in cells at low levels, but their expression is rapidly induced by a variety of inflammatory cytokines, including IL-2, IL-3, IL-4, IL-6, IFN- $\gamma$ and IFN- $\alpha$ (19-21). The up-regulated expression of SOCS1 protein down-regulates the signals induced by these cytokines in negative feedback loops $(19,21)$. Recent studies have shown that SOCS1 is involved in the formation and differentiation of various immune cells and plays an important role in the regulation of innate and adaptive immune responses (20-22).

Studies have shown that the concentration of inflammatory cytokines affects the immunomodulatory effects of MSCs on T cells (23-25). High concentrations of inflammatory factors can cause MSCs to exertan immunosuppressive effect, while insufficient levels of inflammatory factors can cause MSCs to play an immunological enhancement role (23). Zhang et al. (26) indicated that inflammatory factors can stimulate SOCS1 gene expression in MSCs. Currently, the role of SOCS1 in immune regulation of MSCs is still poorly understood. Zhang et al. (26) indicated that interference with SOCS1 expression in MSCs enhanced the immunosuppressive effect of MSCs on T cells. However, the role of SOCS1 in $\mathrm{B}$ cells immunomodulation by MSCs is unclear. Here, we found that, unlike its immunosuppressive effect on $\mathrm{T}$ cells, the SOCS1 gene knockdown of MSCs reversed the inhibition of $\mathrm{B}$ cell differentiation into plasma cells and promoted $\operatorname{IgA}^{+} \mathrm{B}$ cell production.

\section{Materials and Methods}

\section{Animals}

6 8 weeks-old male mice (C57BL/6) were purchased from the Laboratory Animal Center, Institute of Basic Medical Sciences, Beijing, China and maintained under specific pathogen-free conditions. The studies were approved by Animal Care and Use Committee of Tongren University.

\section{Cells}

The MSCs without (MSC/CTLsh) or with SOCS1 knockdown (MSC/SOCS1sh) are identical to those used in our previously published article (26). MSCs were cultured with $\alpha$-MEM (Invitrogen) supplemented with $4 \mathrm{mM}$ L-glutamine, $100 \mathrm{U} / \mathrm{ml}$ penicillin, $100 \mathrm{U} / \mathrm{ml}$ streptomycin and $10 \%$ fetal bovine serum (FBS) at $37^{\circ} \mathrm{C}$ in a $5 \% \mathrm{CO}_{2}$ incubator. $\mathrm{B}$ cells were separated from murine spleens with B220 MicroBead Kit (Miltenyi Biotec) as described previously (27).

\section{Co-cultures}

The cells were incubated in RPMI 1640 medium (Invitrogen) containing 10\% FBS in the presence of different stimulators (group I: $10 \mu \mathrm{g} / \mathrm{ml} \mathrm{LPS}$; group II: $10 \mu \mathrm{g}$ / $\mathrm{ml} \mathrm{LPS}+25 \mathrm{ng} / \mathrm{ml} \mathrm{IL4}$; group III: $10 \mu \mathrm{g} / \mathrm{ml} \mathrm{LPS}+1 \mathrm{ng} / \mathrm{ml}$ TGF- $\beta$ ). For the $\mathrm{B}$ cell proliferation assay, B cells were stained with CFSE and stimulated with LPS, LPS+IL4, LPS + TGF $\beta$ for 22 hours and then cultured alone or with different proportions $(1: 10,1: 20,1: 40,1: 80)$ of MSC/CTLsh or MSC/SOCS1sh. After co-culturing for 36 $\mathrm{h}, \mathrm{B}$ cells were harvested for proliferation measurement using flow cytometry. For B cell activation assay, B cells were stimulated with LPS, LPS+IL4, LPS+TGF $\beta$ for 11 hours and then co-cultured by adding MSC/CTLsh or MSC/SOCS1sh at a ratio of $1: 10$. After 9 hours of co-culture, B cells were labeled with anti-CD40 and anti-CD86 antibodies and assayed for activation by flow cytometry. To evaluate the differentiation of B cells into plasma cells, B cells were stimulated with LPS, LPS+IL4, LPS $+\mathrm{TGF} \beta$ for 23 hours and then co-cultured by adding $1: 10$ MSC/CTLsh or MSC/SOCS1sh. After two days of co-cultivation, $\mathrm{B}$ cells were collected for analysis of plasma cell formation. Finally, for $\operatorname{IgA}^{+} \mathrm{B}$ cell formation assay, B cells were stimulated with LPS for 24 hours and then co-cultured for 3 days with MSC/CTLsh or MSC/SOCS1sh at a ratio of $1: 10$. The whole co-culture was stimulated with 
LPS. After 3 days of co-cultivation, B cells were collected for analysis of $\operatorname{IgA}^{+} \mathrm{B}$ cells.

\section{Monoclonal antibodies and FACS analysis}

The antibodies used were: monoclonal Abs conjugated to APC: -anti-CD220, -anti-CD86; Biotin-anti-IgA; and

A

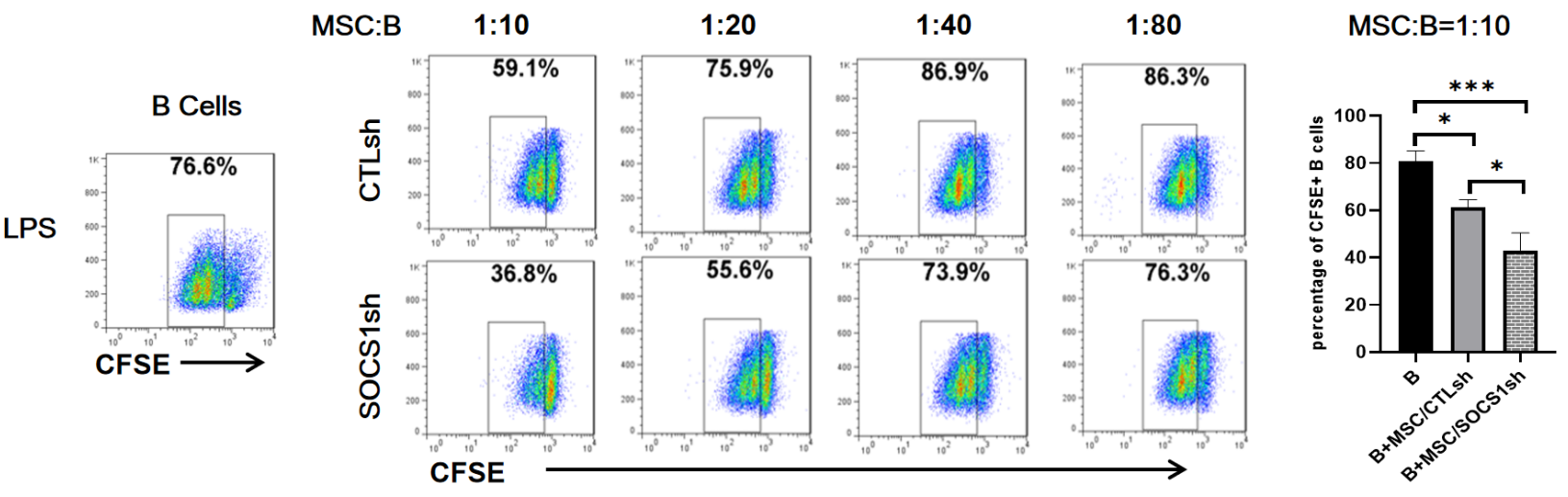

B
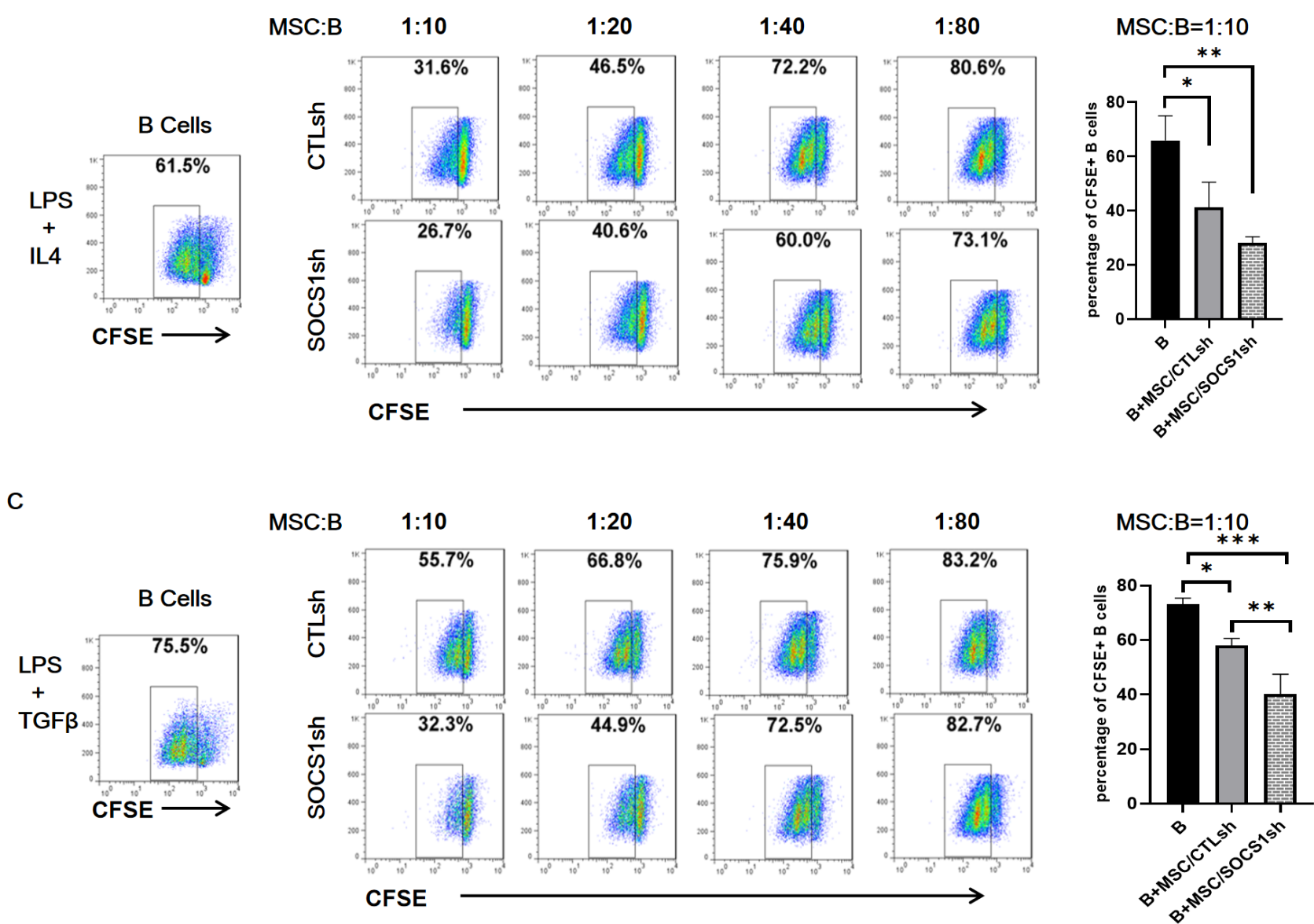

Fig. 1. SOCS1 knockdown aggravates the inhibitory effect of MSCs on B cell proliferation. The B cells isolated from the mouse spleens were labeled with CFSE and stimulated with LPS (A), LPS + IL4 (B), LPS + TGF $\beta$ (C) for 22 hours and then cultured alone or co-cultured with different ratios of MSC/CTLSh or MSC/SOCS1sh under the stimulation of the above cytokines. After 36 hours of co-culture, the B cell proliferation was analyzed by flow cytometry. Data were representative of three independent experiments. ${ }^{*} \mathrm{p}<0.05,{ }^{* *} \mathrm{p}<0.01,{ }^{*} * * \mathrm{p}$ $<0.001$. Note: CTLsh, MSC/CTLsh; SOCS1sh, MSC/SOCS1sh. 
PE: -anti-CD40, -anti-CD138 (all from BD Biosciences). Cells labeled with biotinylated antibodies were visualized by incubation with Phycoerthyrin (PE) conjugated streptavidin. For cell proliferation assays, B cells were labeled with carboxyfluorescein diacetate, succinimidyl ester (CFSE, Invitrogen) as described previously (27). Data were collected at FACS Calibur (Becton Dickinson, San Jose, CA, USA) and analyzed with FlowJo software (TreeStar).

\section{Prostaglandins E2 (PGE2) determination}

MSC/SOCS1sh and MSC/CTLsh were incubated with different doses $(0,0.5$ and $5 \mathrm{ng} / \mathrm{ml})$ of TNF- $\alpha / \mathrm{IFN}-\gamma$ at $37^{\circ} \mathrm{C}, 5 \% \mathrm{CO}_{2}$ for $12 \mathrm{~h}$. Supernatants were collected and precipitated by centrifugation to remove cell debris, and the remaining supernatants were used for PGE2 determination. PGE2 measurement was performed by ELISA (Cayman Chemical, Ann Arbor, MI) according to the manufacturer's instructions. All samples were measured in triplicate.

\section{Statistical analysis}

Statistical analyzes were performed by unpaired two-tailed Student's t-test and one-way analysis of variance (ANOVA) followed by Tukey's multiple comparison post-test. $\mathrm{p}$ values $<0.05$ were considered statistically significant.

\section{Results}

SOCS1 knockdown enhances the inhibitory effect of MSCs on B cell proliferation

To verify the effect of MSCs on B cell proliferation and the role of SOCS1 therein, B cells were co-cultured with different ratios of MSCs (1:10, $1: 20,1: 40$ and $1: 80)$ under the stimulation of LPS (Fig. 1A), LPS+IL4 (Fig.
A

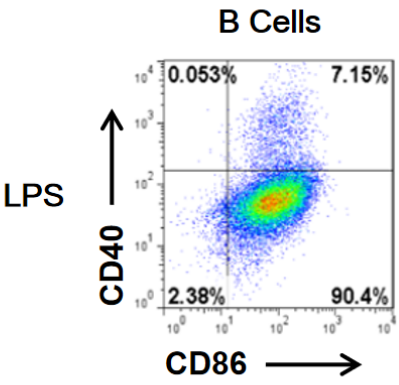

B

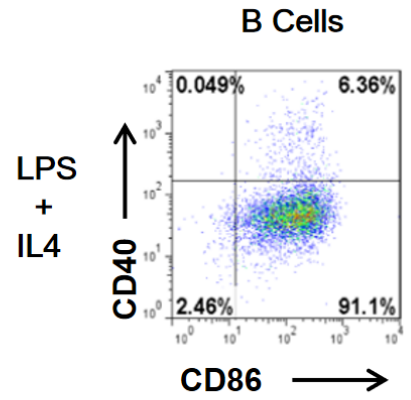

C

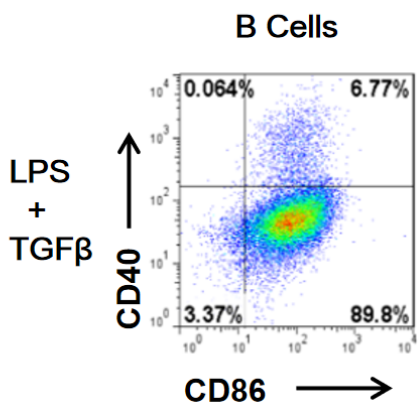

\section{MSC:B}

$1: 10$

CTLsh

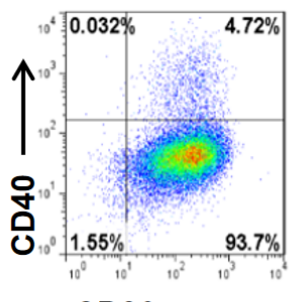

CD86

MSC:B

1:10 CTLsh
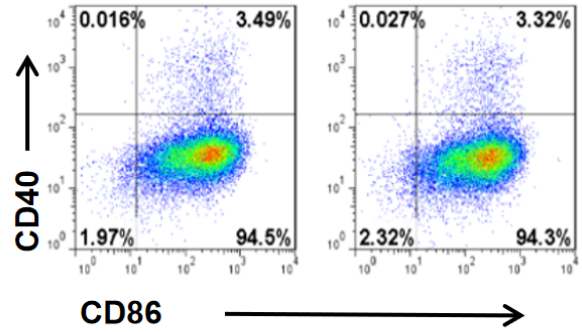

MSC:B

1:10 CTLsh

SOCS1sh

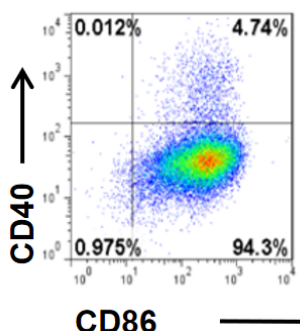

Fig. 2. SOCS1sh has no effect on the inhibition of $B$ cell activation by MSCs. B cells isolated from mouse spleens were stimulated with LPS (A), LPS/IL4 (B) and LPS/TGF $\beta$ (C) for 11 hours and then co-cultured by adding MSC/CTLSh or MSC/SOCS1sh at a ratio of $1: 10$. After 9 hours of co-culture, B cells were labeled with anti-CD40 and anti-CD86 antibodies. B cell activation was analyzed by flow cytometry. Note: CTLsh, MSC/CTLsh; SOCS1sh, MSC/SOCS1sh. 
1B) and LPS+TGF $\beta$ (Fig. 1C). The results showed that under the stimulation of the above three groups of different cytokines, regardless of the MSC/CTLsh or MSC/ SOCS1sh group, the B cell proliferation rate was inversely proportional to the amount of MSCs added. When the ratio of MSCs to B cells was 1 : 10, B cell proliferation was the lowest of all MSCs ratios, regardless of the MSC/CTLsh group or the MSC/SOCS1sh group. Besides, in this MSCs/B cells ratio, the B cell proliferation was significantly less than that of the isolated $\mathrm{B}$ cell group. On the other hand, when the ratio of MSCs to B cells was reduced to a minimum of $1: 80, \mathrm{~B}$ cell proliferation rate was the highest of all ratios. Moreover, the $\mathrm{B}$ cell proliferation rate was also higher than that of the isolated $\mathrm{B}$ cell group. For both LPS (Fig. 1A) and LPS/TGF $\beta$ (Fig. 1C) cytokine-stimulated groups, B cell proliferation in the MSC/SOCS1sh group was significantly lower than the MSC/CTLsh at a ratio of $1: 10$. This difference between the two groups was gradually reduced in $1: 40$ and $1: 80$ ratios. These results indicated that MSCs regulate $B$ cell proliferation in a dose-dependent manner. Low doses of MSCs showed an immune-promoting effect, while high doses of MSCs exerted an immunosuppressive effect. Moreover, the immunosuppression was more pronounced in the MSC/SOCS1sh group.

\section{SOCS1 downregulation has no effect on inhibition of B cell activation by MSCs}

We evaluated the expression of CD40 and CD86 activation markers in B cells to further reveal the role of SOCS1 from MSCs in B cell activation. B cells were co-cultured with MSC/CTLsh or MSC/SOCS1sh under the stimulation of LPS (Fig. 2A), LPS/IL4 (Fig. 2B) and LPS/ TGF $\beta$ (Fig. 2C). The results showed that the percentage of $\mathrm{CD} 40^{+}$and $\mathrm{CD} 86^{+} \mathrm{B}$ cell in MSC/CTLsh group was generally lower than in the isolated $\mathrm{B}$ cell groups in any of the cytokine-stimulated groups. However, there were no differences between MSC/CTLsh and MSC/SOCS1sh groups. These results indicated that MSCs inhibited B cell activation and that SOCS1 knockdown had no influence on this effect.

\section{SOCS1 knockdown reverses the inhibition of B cell differentiation into plasma cells by MSCs}

To further clarify the effect of MSCs on B cell differentiation, B cells were cultured with MSCs at a ratio of $1: 10$ under stimulation of LPS (Fig. 3A), LPS/IL4 (Fig. 3B) and LPS/TGF $\beta$ (Fig. 3C). The results showed that,
A

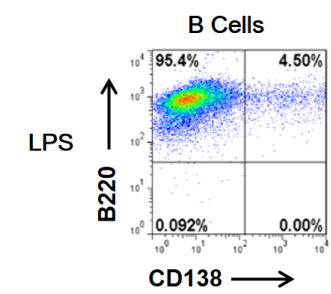

B

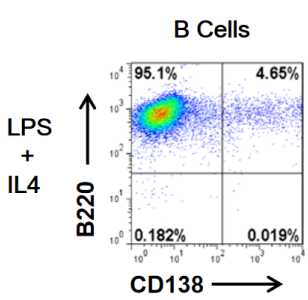

C

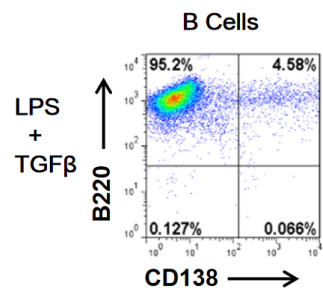

\section{MSC:B}

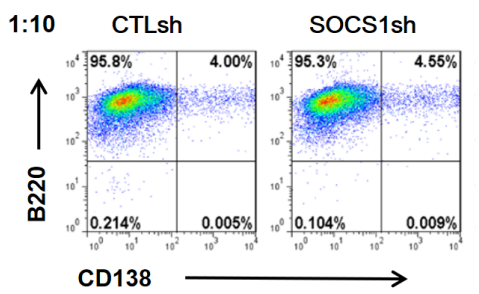

MSC:B

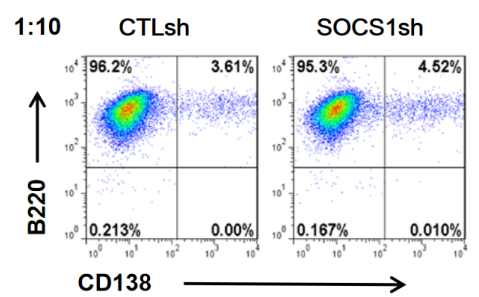

MSC:B

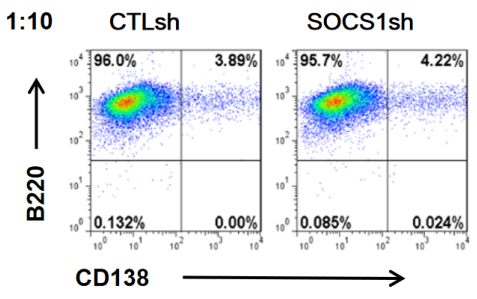

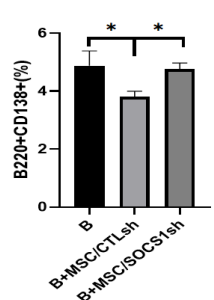
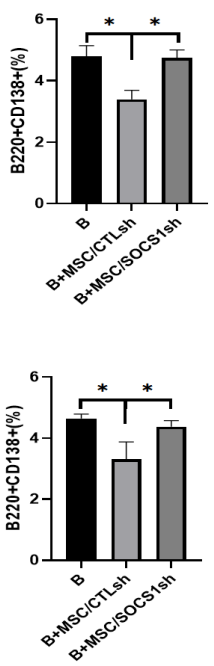

Fig. 3. Knockdown of SOCS1 reverses the inhibition of plasma cell formation by MSCs. B cells were stimulated with LPS (A), LPS/IL4 (B), LPS/TGF $\beta$ (C) for 23 hours and then co-cultured by adding MSC/CTLsh or MSC/SOCS1sh at a ratio of $1: 10$. After two days of co-cultivation, B cells were harvested, labeled with anti-B220 and anti-CD138 antibodies and analyzed for plasma cell formation by flow cytometry. Data were representative of three independent experiments. ${ }^{*} p<0.05$. Note: CTLsh, MSC/CTLsh; SOCS1sh, MSC/SOCS1sh. 
compared to the isolated B cells group, the MSC/CTLsh co-culture inhibited the expression of the plasma cell marker CD138, regardless of the cytokine-stimulated group. Remarkably, MSC/SOCS1sh has abolished the inhibition of CD138 expression induced by MSC/CTLsh. These results indicated that SOCS1 knockdown could reverse the inhibitory effect of MSCs in the last stage of B cell differentiation.

\section{MSCs promoted $\lg \mathrm{A}^{+}$B cell formation after SOCS1 knockdown}

IgA is the most abundant immunoglobulin in the human body and has an irreplaceable role in mucosal immunity (28). More than $80 \%$ of plasma cells produce IgA in mucosa-associated lymphoid tissues (28). The effect of MSCs on $\mathrm{IgA}^{+} \mathrm{B}$ cells production is still unclear. Here, we examined the formation of $\mathrm{IgA}^{+} \mathrm{B}$ cells co-cultured with MSC/CTLsh or MSC/SOCS1sh (Fig. 4). We found no significant differences in $\operatorname{IgA}^{+} \mathrm{B}$ cell production in these two groups compared to the isolated B cells group. However, we showed that the $\operatorname{IgA}^{+} \mathrm{B}$ cell production was significantly higher in the MSC/SOCS1sh than in the MSC/CTLsh group (Fig. 4). These results indicated that MSCs promoted the production of $\mathrm{IgA}^{+} \mathrm{B}$ cells after SOCS1 knockdown.

\section{SOCS1 knockdown increases PGE2 secretion of MSCs}

We evaluated PGE2 secretion in MSCs stimulated by TNF- $\alpha / \mathrm{IFN}-\gamma$ inflammatory factors (Fig. 5), because PGE2 has been reported to be involved in B cell development (29). The results showed that the secretion of PGE2 increased in the MSC/CTLsh and MSC/SOCS1sh groups after TNF- $\alpha / \mathrm{IFN}-\gamma$ stimulation. Besides, the PGE2 pro- duction in MSC/SOCS1sh was significantly higher than in the MSC/CTLsh group (Fig. 5). These results indicated that SOCS1 knockdown can promote PGE2 production in MSCs.

\section{Discussion}

MSCs have great potential for application in the treatment of certain immune-injured diseases due to their immunomodulatory properties and damage repair ability (1). However, the unstable immunomodulatory effects of MSCs on B cells and an inadequate understanding of the underlying mechanisms limit their use in the treatment of diseases associated with abnormal $\mathrm{B}$ cells. In the pres-

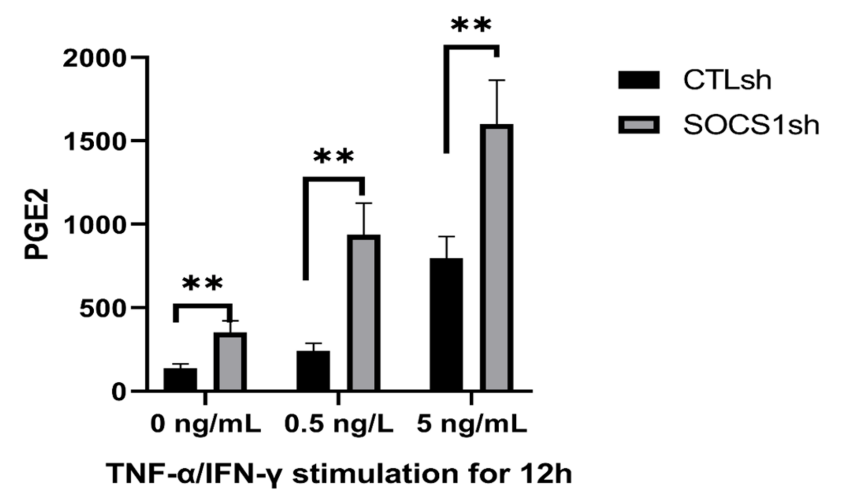

Fig. 5. SOCS1 knockdown promotes PGE2 secretion by MSCs. MSC/CTLsh or MSC/SOCS1sh were stimulated with different doses $(0,0.5$ and $5 \mathrm{ng} / \mathrm{ml})$ of TNF- $\alpha / \mathrm{IFN}-\gamma$ for $12 \mathrm{~h}$ and then the level of PGE2 in the culture medium was measured by ELISA. Data were representative of three independent experiments. ${ }^{* *} \mathrm{p}<0.01$. Note: CTLsh, MSC/CTLsh; SOCS1sh, MSC/SOCS1sh.
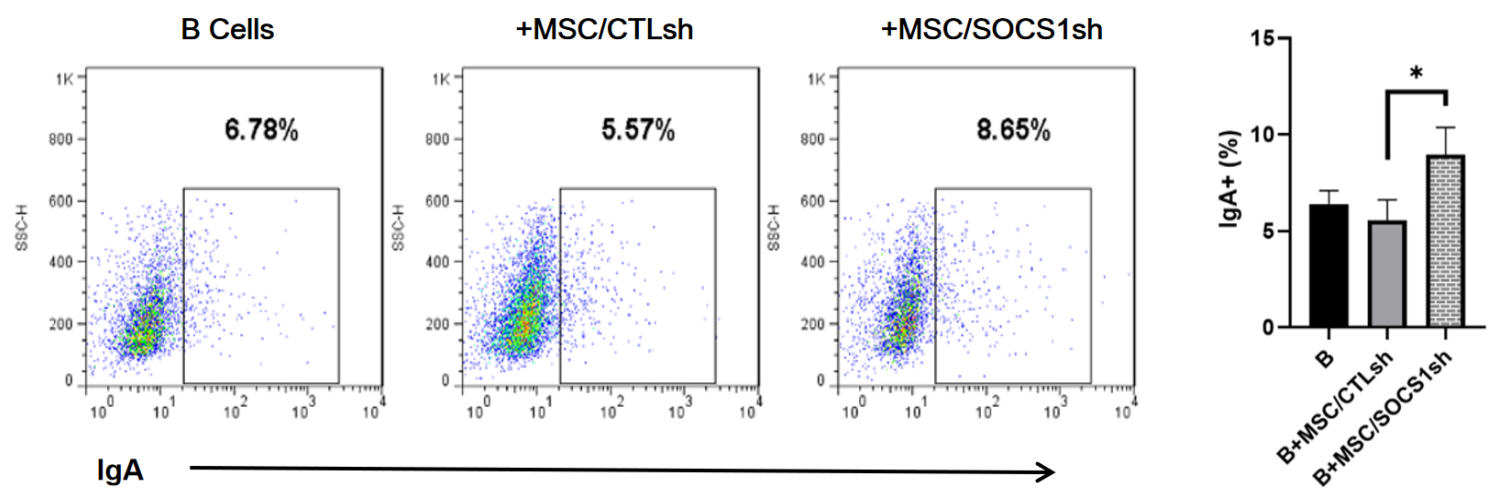

Fig. 4. MSC/SOCS1sh promotes $\operatorname{IgA}^{+} \mathrm{B}$ cell formation. Purified B cells were stimulated with LPS for 24 hours, then MSC/CTLsh or MSC/SOCS1sh was added at a ratio of $1: 10$ and co-cultured for 3 days. All cultures were stimulated with LPS. After co-cultivation for 3 days, the percentages of $\operatorname{IgA}^{+} \mathrm{B}$ cells were determined by FACS, which are showed within the squares. Data were representative of three independent experiments. ${ }^{*} \mathrm{p}<0.05$. Note: CTLsh, MSC/CTLsh; SOCS1sh, MSC/SOCS1sh. 
ent work, by co-culture assays of MSCs and B cells, we found that MSCs inhibited B cell proliferation and differentiation and that this inhibitory effect could be regulated by SOCS1 from MSCs.

The few reported studies on B cells immune regulation by MSCs were not sufficient to define the effects of MSCs on B cell function, as they present conflicting data. Here, our results indicated that MSCs inhibited B cell function, which was consistent with some previous reports $(10,11$, $15,16,18)$.

The immune regulation of $\mathrm{T}$ cells by MSCs is related to the concentration of inflammatory factors. Previous studies have shown that excessive inflammatory factors can induce MSCs to inhibit $\mathrm{T}$ cell responses (23, 30). However, the effects of these factors on $\mathrm{B}$ cell function are poorly understood. MSCs stimulated by the inflammatory factor IFN- $\gamma$ have been reported to enhance the inhibition of $\mathrm{B}$ cell proliferation (12). Moreover, it is known that immune cells can secrete inflammatory factors including TNF- $\alpha$, IFN- $\gamma$ and ILb in response to stimuli provided by LPS, TGF- $\beta$ and ConA. Our experiments showed that differences in co-culture cultivation affects the immunomodulatory effects of MSCs. When MSCs were implanted before B cells addition or immediately after B cells implantation, MSCs promoted, but did not inhibit $B$ cell proliferation (data not shown). On the other hand, when B cells were added $10 \mathrm{~h}$ after stimulation of MSCs by TNF- $\alpha / \mathrm{IFN}-\gamma$ (data not shown) or when MSCs were co-cultured $20 \mathrm{~h}$ after $\mathrm{B}$ cells implantation, the proliferation of B cells was completely inhibited (Fig. 1). Therefore, the mode of planting MSCs or B cells probably affects the concentration of inflammatory factors in the co-culture. When B cells receive stimulating factors for a long period (for example, up to 20 hours), the concentration of inflammatory factors secreted by them in the medium may be high. If MSCs are added at this time, MSCs will be induced to exert an immunosuppressive effect. In contrast, whether MSCs are seeded before adding B cells or the implantation interval between B cells and MSCs is short, the inflammatory factors in the culture medium are insufficient to trigger the immunosuppressive effect of MSCs. However, even at lower concentrations, inflammatory factors are still able to induce the immune promoting effect of MSCs. Based on these observations, it can be concluded that the different immunomodulatory effects of MSCs on B cells may be highly correlated with the different degrees of inflammation. Moreover, these inflammation degrees are the result of different methods of planting MSCs or B cells. For the first time, it is reported that the sequence of implantation of MSCs and B cells in co-cultures affects the regulation of B cells by MSCs.

Inflammatory factors are able to induce SOCS1 expression and can be regulated by its negative feedback (20, 21). Zhang et al. (26) showed that inflammatory factors trigger SOCS1 expression in MSCs, while SOCS1 gene knockdown enhances MSCs to inhibit T cell proliferation. In the present study, our data indicated that SOCS1 gene knockdown in MSCs also increased the inhibitory effect of MSCs on B cell proliferation. In addition, we showed that MSC/CTLsh and MSC/SOCS1sh regulated of B cell proliferation in a dose-dependent manner. That is, as the dose of MSCs increases, the regulation of $\mathrm{B}$ cell proliferation by MSCs is gradually shifted from a promoting effect to an inhibitory one. The dose-dependent regulation of MSCs observed in our experiments is consistent with a previous study (11). This effect may be due to the fact that certain factors secreted by MSCs accumulate to a certain extent (threshold) to inhibit B cell proliferation, otherwise they promote B cell proliferation.

Some studies $(1,31,32)$ have shown that MSCs can secrete PGE2 cytokines to inhibit T cell responses. Although PGE2 has been reported to be involved in B cell development (29), the role of PGE2 in the regulation of B cells by MSCs remains unknown. Our results indicated that SOCS1 knockdown in MSCs could increase PGE2 production. Downregulation of SOCS1 abolished the inhibitory effect of MSCs on B cell differentiation and promoted $\operatorname{IgA}^{+} \mathrm{B}$ cell formation, which may be related to PGE2 and nitric oxide (NO) overproduction. PGE2 has been reported to promote IgA formation (33) and that $\mathrm{NO}$ production promotes the generation of $\operatorname{IgA}^{+}$plasma cells $(28,34)$. Zhang et al. (26) have shown that MSC/SOCS1sh inhibited $\mathrm{T}$ cell proliferation by promoting $\mathrm{NO}$ production. In the present study, the increase in $\operatorname{IgA}^{+} \mathrm{B}$ cells in the MSC/SOCS1sh group may be related to the contribution of NO in addition to PGE2. Although MSCs also produce NO and PGE2, co-culture with $\mathrm{B}$ cells does not promote the formation of $\operatorname{IgA}^{+} \mathrm{B}$ cells. This can be related to other MSC-derived factors that suppress $\operatorname{IgA}^{+}$ $\mathrm{B}$ cell formation. Following SOCS1 gene knockdown in MSCs, the inhibitory effect of other factors on IgA production may be masked by the large amount of NO and PGE2 that promote IgA production. Remarkably, the specific mechanism by which SOCS1 regulates the interaction between MSCs and B cells remains to be further studied.

In conclusion, we found that the different immunoregulatory effects of MSCs on B cells are related to differences in co-culture cultivation. Furthermore, we revealed a novel role of SOCS1 in regulating B cell function by MSCs. These results provided new insights into B-cell im- 
munomodulation by MSCs that may help to develop new treatments based on the use of MSCs for B cell mediated immune diseases.

\section{Acknowledgments}

This study was supported by Grants from Basic Research Project of Guizhou Science and Technology Department (No. 20171188 to LZ), the National Natural Science Foundation of China (No. 81771998, No. 31971285 to XXJ; No.31702097 to ZYW), Doctoral Scientific Research Start-up Foundation from Tongren University (No. trxyDH1524 to LZ), Beijing National Science Foundation (No.7202149 to XXJ), Projects in the Guizhou Science and Technology Pillar Program (No. 20182791 to LZ) and Basic Research Project of Tongren Science and Technology Bureau (No. 2015163 to LZ, No. 20126317 to LZ), Hunan Natural Science Foundation (No. 2016JJ6141 to WBG).

\section{Potential Conflict of Interest}

The authors have no conflicting financial interest.

\section{References}

1. Wang Y, Chen X, Cao W, Shi Y. Plasticity of mesenchymal stem cells in immunomodulation: pathological and therapeutic implications. Nat Immunol 2014;15:1009-1016

2. Franquesa $M$, Hoogduijn MJ, Bestard O, Grinyó JM. Immunomodulatory effect of mesenchymal stem cells on B cells. Front Immunol 2012;3:212

3. Bernardo ME, Fibbe WE. Mesenchymal stromal cells: sensors and switchers of inflammation. Cell Stem Cell 2013;13: 392-402

4. Ren G, Zhang L, Zhao X, Xu G, Zhang Y, Roberts AI, Zhao RC, Shi Y. Mesenchymal stem cell-mediated immunosuppression occurs via concerted action of chemokines and nitric oxide. Cell Stem Cell 2008;2:141-150

5. Akiyama K, Chen C, Wang D, Xu X, Qu C, Yamaza T, Cai T, Chen W, Sun L, Shi S. Mesenchymal-stem-cell-induced immunoregulation involves FAS-ligand-/FAS-mediated T cell apoptosis. Cell Stem Cell 2012;10:544-555

6. Fan L, Hu C, Chen J, Cen P, Wang J, Li L. Interaction between mesenchymal stem cells and B-cells. Int J Mol Sci 2016;17:E650

7. Bonnaure G, Gervais-St-Amour C, Néron S. Bone marrow mesenchymal stem cells enhance the differentiation of human switched memory B lymphocytes into plasma cells in serum-free medium. J Immunol Res 2016;2016:7801781

8. Ji YR, Yang ZX, Han ZB, Meng L, Liang L, Feng XM, Yang SG, Chi Y, Chen DD, Wang YW, Han ZC. Mesenchymal stem cells support proliferation and terminal differentiation of B cells. Cell Physiol Biochem 2012;30: 1526-1537
9. Traggiai E, Volpi S, Schena F, Gattorno M, Ferlito F, Moretta L, Martini A. Bone marrow-derived mesenchymal stem cells induce both polyclonal expansion and differentiation of B cells isolated from healthy donors and systemic lupus erythematosus patients. Stem Cells 2008;26: 562-569

10. Asari S, Itakura S, Ferreri K, Liu CP, Kuroda Y, Kandeel F, Mullen Y. Mesenchymal stem cells suppress B-cell terminal differentiation. Exp Hematol 2009;37:604-615

11. Corcione A, Benvenuto F, Ferretti E, Giunti D, Cappiello V, Cazzanti F, Risso M, Gualandi F, Mancardi GL, Pistoia V, Uccelli A. Human mesenchymal stem cells modulate B-cell functions. Blood 2006;107:367-372

12. Luk F, Carreras-Planella L, Korevaar SS, de Witte SFH, Borràs FE, Betjes MGH, Baan CC, Hoogduijn MJ, Franquesa $M$. Inflammatory conditions dictate the effect of mesenchymal stem or stromal cells on B cell function. Front Immunol 2017;8:1042

13. Che N, Li X, Zhang L, Liu R, Chen H, Gao X, Shi S, Chen W, Sun L. Impaired B cell inhibition by lupus bone marrow mesenchymal stem cells is caused by reduced CCL2 expression. J Immunol 2014;193:5306-5314

14. Schena F, Gambini C, Gregorio A, Mosconi M, Reverberi D, Gattorno M, Casazza S, Uccelli A, Moretta L, Martini A, Traggiai E. Interferon- $\gamma$-dependent inhibition of $\mathrm{B}$ cell activation by bone marrow-derived mesenchymal stem cells in a murine model of systemic lupus erythematosus. Arthritis Rheum 2010;62:2776-2786

15. Liu O, Xu J, Ding G, Liu D, Fan Z, Zhang C, Chen W, Ding Y, Tang Z, Wang S. Periodontal ligament stem cells regulate B lymphocyte function via programmed cell death protein 1. Stem Cells 2013;31:1371-1382

16. Tabera S, Pérez-Simón JA, Díez-Campelo M, SánchezAbarca LI, Blanco B, López A, Benito A, Ocio E, Sánchez-Guijo FM, Cañizo C, San Miguel JF. The effect of mesenchymal stem cells on the viability, proliferation and differentiation of B-lymphocytes. Haematologica 2008;93:1301-1309

17. Khare D, Or R, Resnick I, Barkatz C, Almogi-Hazan O, Avni B. Mesenchymal stromal cell-derived exosomes affect mRNA expression and function of B-lymphocytes. Front Immunol 2018;9:3053

18. Che N, Li X, Zhou S, Liu R, Shi D, Lu L, Sun L. Umbilical cord mesenchymal stem cells suppress B-cell proliferation and differentiation. Cell Immunol 2012;274: 46-53

19. Krebs DL, Hilton DJ. SOCS proteins: negative regulators of cytokine signaling. Stem Cells 2001;19:378-387

20. Yoshimura A, Suzuki M, Sakaguchi R, Hanada T, Yasukawa H. SOCS, inflammation, and autoimmunity. Front Immunol 2012;3:20

21. Kubo M, Hanada T, Yoshimura A. Suppressors of cytokine signaling and immunity. Nat Immunol 2003;4:1169-1176

22. Palmer DC, Restifo NP. Suppressors of cytokine signaling (SOCS) in T cell differentiation, maturation, and function. Trends Immunol 2009;30:592-602 
23. Li W, Ren G, Huang Y, Su J, Han Y, Li J, Chen X, Cao K, Chen Q, Shou P, Zhang L, Yuan ZR, Roberts AI, Shi S, Le AD, Shi Y. Mesenchymal stem cells: a double-edged sword in regulating immune responses. Cell Death Differ 2012;19:1505-1513

24. Rodriguez LA 2nd, Mohammadipoor A, Alvarado L, Kamucheka RM, Asher AM, Cancio LC, Antebi B. Preconditioning in an inflammatory milieu augments the immunotherapeutic function of mesenchymal stromal cells. Cells 2019;8:E462

25. Ankrum JA, Ong JF, Karp JM. Mesenchymal stem cells: immune evasive, not immune privileged. Nat Biotechnol 2014;32:252-260

26. Zhang L, Dang RJ, Li H, Li P, Yang YM, Guo XM, Wang XY, Fang NZ, Mao N, Wen N, Jiang XX. SOCS1 regulates the immune modulatory properties of mesenchymal stem cells by inhibiting nitric oxide production. PLoS One 2014;9:e97256

27. Zhang L, Dang RJ, Yang YM, Cui DC, Li P, Ni YL, Hao T, Wang C, Jiang XX, Fang NZ. Delta-like-1 changes the immunomodulatory property of OP9 cells. Stem Cells Int 2016;2016:1628352

28. Tezuka H, Abe $Y$, Iwata $M$, Takeuchi $H$, Ishikawa $H$, Matsushita M, Shiohara T, Akira S, Ohteki T. Regulation of IgA production by naturally occurring TNF/iNOS-producing dendritic cells. Nature 2007;448:929-933
29. Brown DM, Phipps RP. Characterization and regulation of prostaglandin E2 receptors on normal and malignant murine B lymphocytes. Cell Immunol 1995;161:79-87

30. Renner P, Eggenhofer E, Rosenauer A, Popp FC, Steinmann JF, Slowik P, Geissler EK, Piso P, Schlitt HJ, Dahlke MH. Mesenchymal stem cells require a sufficient, ongoing immune response to exert their immunosuppressive function. Transplant Proc 2009;41:2607-2611

31. Najar M, Raicevic G, Boufker HI, Fayyad Kazan H, De Bruyn C, Meuleman N, Bron D, Toungouz M, Lagneaux L. Mesenchymal stromal cells use PGE2 to modulate activation and proliferation of lymphocyte subsets: combined comparison of adipose tissue, Wharton's Jelly and bone marrow sources. Cell Immunol 2010;264:171-179

32. Yañez R, Oviedo A, Aldea M, Bueren JA, Lamana ML. Prostaglandin E2 plays a key role in the immunosuppressive properties of adipose and bone marrow tissue-derived mesenchymal stromal cells. Exp Cell Res 2010;316:3109-3123

33. Garrone P, Galibert L, Rousset F, Fu SM, Banchereau J. Regulatory effects of prostaglandin E2 on the growth and differentiation of human B lymphocytes activated through their CD40 antigen. J Immunol 1994;152:4282-4290

34. Lee MR, Seo GY, Kim YM, Kim PH. iNOS potentiates mouse Ig isotype switching through AID expression. Biochem Biophys Res Commun 2011;410:602-607 